\title{
Systematic Review: Intersection between Communication and Knowledge
}

\author{
Andreia de Bem Machado ${ }^{1 *}$, Maria Jose Souza ${ }^{2}$, Araci Hack Catapan ${ }^{3}$ \\ ${ }^{1}$ Uniasselvi and AeroTD, College of Aviation, BRAZIL \\ ${ }^{2}$ CIEO - Algarve University and BRUL-IUL, PORTUGAL \\ ${ }^{3}$ UFSC, BRAZIL
}

*Corresponding Author: andreiadebem@gmail.com

Citation: Machado, A. de B., Souza, M. J. and Catapan, A. H. (2019). Systematic Review: Intersection between Communication and Knowledge. Journal of Information Systems Engineering \& Management, 4(1), em0086. https://doi.org/10.29333/jisem/5741

Published: March 24, 2019

\begin{abstract}
Advances in technological possibilities have made communication present in different media and spaces. By enabling interaction between different countries, by becoming a facilitator between knowledge and innovation in the globalized world, it has opened frontiers by providing innovations in various sectors of the knowledge society. In this sense, the objective in this article is to map the intersection of communication, innovation and knowledge in the globalized world. To that end, the methodology used in the research was the systematic search of literature that pointed out that the intersection is motivated by the use of innovative technologies in the process of knowledge sharing, and studies are still scarce in this area. It is possible to perceive, further, that this intersection is branched out, through Social Sciences, Business, Management and Accounting, Computer Science, Medicine, Engineering, Decision Sciences, Nursing, Arts and Humanities, Economics, Econometrics and Finance, Psychology, aligned Health Professions, Agricultural and Biological Sciences, Biochemistry, Genetics and Molecular Biology, Energy, Environmental Science, Mathematics, Materials Science, Multidisciplinary, Neuroscience, Pharmacology, Toxicology and Pharmaceutical and Veterinary.
\end{abstract}

Keywords: globalization, communication, innovation and knowledge

\section{INTRODUCTION}

The possibilities of increasingly interactive resources in the globalized world have changed the conception of communication and sharing of knowledge linked to innovative technologies. Technology linked to communication contributes to the access of knowledge and this has been expanded through digital communication networks. The innumerable paths covered by innovation linked to technology point to different realities and orientations in the communication process coming from social networks.

In this scenario sharing knowledge is a way of making one human being's knowledge available to other people so that it can be absorbed and handled by them. The use of the term "share" demands from the human being who possesses knowledge to use some conscious action, which does not make them renounce the property of knowledge, but will result in a joint property of them and the recipient (IPE, 2003). This sharing occurs in all dimensions of society, at school and in organizations. Within the organization this can lead to innovation within the company, since the human capital stock of the company is an important determinant of its capacity to innovate. Thus, any increase in ways to share through company-sponsored training can lead to more innovation (Dostie, 2017). Given that innovation strategy (Pavlov, 2017) is an important factor for the successful realization of 
products and technologies, organizational and management innovations and, consequently, the improvement of the market positions of innovative companies.

This allows an influence on the behavior of people and organizations, for Chamom (2007) culture influences the behavior of people and organizations. The culture of society comprises shared values, habits, uses and customs, codes of conduct, traditions and goals that are passed on from the older generations to the new ones and so on.

Cultures are based on a set of beliefs, sharing knowledge and ideas about the nature of life through technologies that, through innovation, translate knowledge through the act of communicating. These within the organization (Bejinaru and Bãeşu, 2017) can lead to change and innovation management, considering the management approach of people, resources and processes. Considering that the sharing of knowledge within any organization through the act of communicating generates an innovative culture that must be supported by individuals in power (Moussa, Mcmurray and Muenjohn, 2018).

In organizations, besides communication (Olokundun et al., 2018) there is also a strong link between innovation and employee entrepreneurial behavior that results in growth and organizational performance. This innovation may be digital innovation, Lyytinen, Majchrzak and Song (2017), understood as the use of digital technology during the innovation process. Digital innovation can also be used to describe, in whole or in part, the outcome of innovation. Another concept also applied to organizations is corporate innovation that can be the driving force behind institutional change and its success can be largely attributed to employees (Delmas and Pekovic, 2016).

Based on this contextualization, the objective in this article is to map the intersection of communication, innovation and knowledge in the globalized world. To do so, the article is organized in five sections. The first one presented here titled introduction presents a context of research. In the second section, the methodological procedures traced in the research are described. In the third section, the data, the results and a bibliometric analysis of this research are presented. In the fourth section, the final considerations are presented showing the relevance of communication, innovation and knowledge. And finally, in the fifth section, the references used to construct this article are listed.

\section{METHODOLOGICAL TRACK}

To meet the objective of this research, we worked from an exploratory-descriptive view with the inductive method that allowed to delineate the theme, to increase the familiarity of the researchers, from sufficient data, and to infer a new conception from the traveled path (Marconi and Lakatos, 2010).

As a method of literature research, a systematic search in an online database was used, followed by a bibliometric analysis of the results. Bibliometrics is an information science methodology that uses mathematical and statistical methods to map documents and publication data. Bibliometrics allows the organization and quantitative analysis of relevant data such as: production by region; timeline of publications; research by area of knowledge; study citation count; impact factor of a scientific publication among others (Feather and Sturges, 2003; Santos and Kobaschi, 2009). This analysis allows the systematization of the results of a research and the minimization of the occurrence of possible biases when looking at a certain theme.

For the bibliometric analysis, the study was organized in three distinct stages: planning, gathering and result. These stages happened in an integrated way to answer the problem defined according to the general objective of the research, namely: Which intersections are between communication, innovation and knowledge sharing?

Planning began in June 2017, when the research was conducted. In the planning scope, the Scopus database was defined as relevant $<\mathrm{http}: / /$ www.scopus.com $>$, due to its interdisciplinary character, its constant updating and because it is one of the major bases of abstracts and references of peer-reviewed scientific literature. Following the problematic, the terms of search were delimited, namely: "Communication and innovation and knowledge sharing" as a basic principle for the search, we chose to use the terms in the "title", "abstract" and "keyword" fields, without any temporal restriction, language restriction or other restrictions that may limit the result.

In the data collection phase was recovered a total of 248 indexed articles, with the first record dated from 1988 and the last one from 2016.

As result of this data collection, it was identified that the works were written by 160 authors, linked to 150 institutions. 140 keywords were used to identify and index the publications, which are distributed in 22 areas of knowledge. It was identified that of the 248 scientific papers, all are peer-reviewed articles composing the sample for a bibliometric analysis in the area of Social Sciences, Business, Management and Accounting, Computer Science, Medicine, Engineering, Decision Sciences, Nursing, Arts and Humanities, Economics, Econometrics and Finance, Psychology, aligned Health Professions, Agricultural and Biological Sciences, Biochemistry, Genetics and Molecular Biology, Energy, Environmental Science, Mathematics, Materials Science, Multidisciplinary, Neuroscience, Pharmacology, Toxicology and Pharmaceuticals and Veterinarian allowing to weave the state of the art of the theme from the consulted database. 


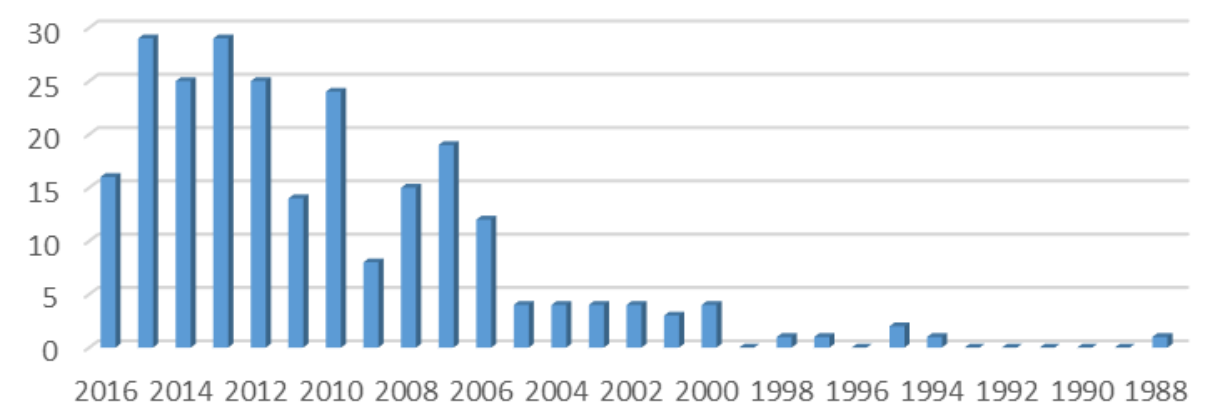

Figure 1. Distribution of work per year

Source: Authors (2017)

For the bibliometric evaluation of the results, the results were exported to a bibliographic management software called EndNoteWeb (Web-based software) and in an integrated way, a data sheet was organized. Thus, the relevant information was classified according to: temporal distribution; main authors, institutions and countries in evidence; type of publication in the area; main keywords and most referenced works.

\section{PRESENTATION OF DATA AND DEBATES}

Initially the temporal distribution of the works was analyzed, which allowed to identify that the first publication is from 1988 with one article followed by 5 years without publication, that is, from 1989 to 1993 there was no record. In 1994 there was an isolated publication and in 1995 two articles were published. 1996 there were no publications. 1997 there was one and in 1998 also one. 1999 three publications and in the year 2000 four publications. 2001 there were three and 2002, 2003, 2004 and 2005 there were 4 publications each year respectively. In the year 2006 there was a considerable increase in publications with 12 articles. In 2007 another increase in publications with 19 published articles. In 2008 there was a drop with 15 publications, followed by 2009 with 8 published documents. In 2010 an increase in publications with 24 published articles. In 2011 there was a decrease with 14 publications. In 2012 there was an increase again with 25 articles published. In 2013 another increase with 29 articles and 2014 followed with 24 articles. In 2015, there was a small increase with 29 indexed articles, but in 2016 a decrease was again identified with 16 published articles. This frequency shows discontinuity and lack of research in the area. For better visualization Figure 1 was elaborated.

The first article published in 1988 was titled Integration across institutions: IAIMS extended by Broering, Feng, and Matheson. This article discussed how technologies contribute to the information world. Explains that electronic technologies are transforming the way we deal with information and the means used to seek knowledge. What once seemed beyond reach - that computer systems, communications, information and knowledge could be harmoniously combined to convey information via networks - is a reality today.

In 1994 the article entitled Making research useful to the practicing nurse by author Akinsanya was published. In it is discussed the problem of the development of nursing research and the challenge of establishing its relevance and utility for the area. The article highlights the need to share knowledge in the nursing area through research and publications.

In 1995 there were two publications Linking frontline work and state-of-the-art knowledge. A community exchange system by Indyk, Belville, and Taking the private voice public sharing nursing knowledge by Chandler. The first article discusses the challenges of complex medical and social tools, where local providers should participate in information exchange, resource sharing, continuing education, and service coordination. A community exchange system, flexible enough to share and adapt new knowledge, and capable of providing continuous multidisciplinary training and education in different contexts of practice. This interconnection as made explicit in the article provides a community exchange system with links between disciplines within a medical center, allowing communication among local community-based organizations and networks between the two settings. The second article is not available for reading. 


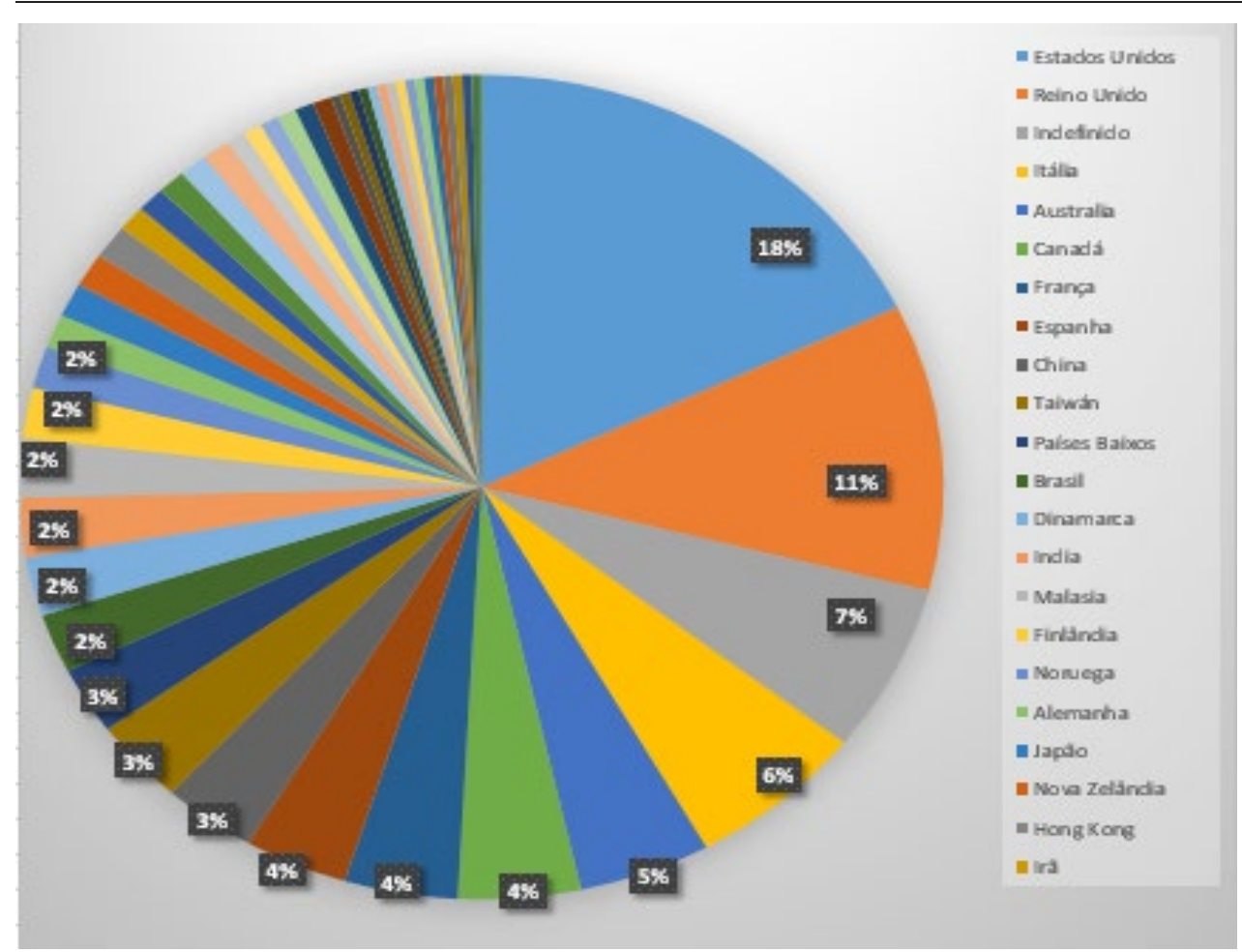

Figure 2. Distribution of research by country

Source: Authors (2017)

In the year 2017, during the period of the research, two articles were found available for reading. In the first article entitled "An empirical research on relationships between subjective judgement, technology acceptance tendency and knowledge transfer" by the authors Yu-Hsi Yuan, Sang-Bing Tsai, Chien-Yun Dai, Hsiao-Ming Chen, Wan-Fei Chen, Chia-Huei Wu, Guodong Li, Jiangtao Wang was discussed the sharing of knowledge. This sharing was done through mobile devices. According to Yuan et al. (2017) this exchange of information promotes the exchange of ideas which generates organizational knowledge, creating more contact with clients and enriching its network of services of the organization.

The second article available for reading found in the year 2017 entitled "Farmer cooperation as a means for creating local food systems-Potentials and challenges" by Lutz, J., Smetschka, B., Grima, N., discusses the issue of innovation in knowledge sharing in the agricultural scenario. According to Lutz, Smetschka e Grima (2017) sharing knowledge generates the development of know-how which helps to optimize local systems of agriculture and food supply resulting in innovation in agriculture.

It is noted with this revision of literature that in all the dimensions of society innovation is fundamental for advances in the economic scenario (ZONTA; AMAL, 2018).

It is noticed that the researches in the area can be considered incipient, because they are presented, according to quantitative analysis, in small proportion and ascendancy with moments of discontinuity for up to two consecutive years. These data allow us also to point out that in the globalized world there is a lack of research about practices through communication networks innovating the way of communicating and sharing knowledge.

From a systemic perspective and directed to the fifty-five studies, a diverse list of countries stands out in the research regarding communication, innovation and knowledge sharing in the formation of the individual in the globalized world. With a significant spot the United States has an average of $18 \%$ of publications, a total of 54 articles. The United Kingdom comes in second with $11 \%$ of the publications, that is, 34 works, and Brazil is in 12 th place with only $2 \%$ of the publications, which makes it possible to see that this area is not strong as research and practice in the national scenario, according to Figure 2.

Figure 3 shows the countries involved in publications indexed in the Scopus database. 


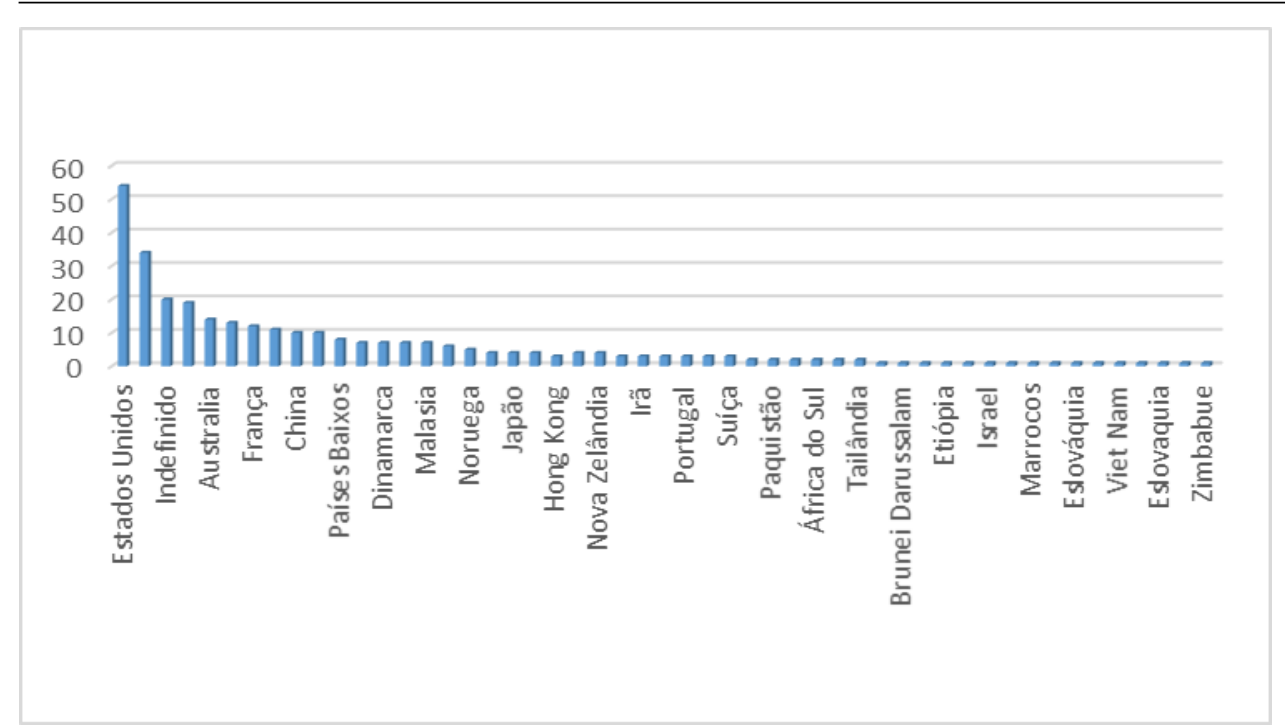

Figure 3. Distribution of research by country

Source: Authors (2017)

Table 1. Authors with the highest number of publications in the area, their affiliations and countries Source: Authors (2017)

\begin{tabular}{|c|c|c|c|}
\hline Author & $\begin{array}{l}\text { Number of } \\
\text { publications }\end{array}$ & Affiliation & Country \\
\hline Lin, H.F. & 3 & $\begin{array}{l}\text { National Taiwan Ocean University, Department of Transportation and Transportation } \\
\text { Management }\end{array}$ & Taiwan \\
\hline Passiante, G. & 3 & Universita del Salento, Innovation Engineering Department, Lecce, & Italy \\
\hline Banerjee, P. & 2 & Jagiroad College, Department of Physics, & India \\
\hline Boyce, R.A. & 2 & $\begin{array}{l}\text { University of Southern Queensland, Centre for Rural and Remote Area Health, } \\
\text { Toowoomba }\end{array}$ & Australia \\
\hline Braithwaite, J. & 2 & $\begin{array}{l}\text { Macquarie University, Center for Healthcare Resilience and Implementation Science, North } \\
\text { Ryde, }\end{array}$ & Australia \\
\hline Chang, C.C. & 2 & $\begin{array}{l}\text { National Taiwan Normal University, Department of Human Resource Development and } \\
\text { Applied Technology, Taipei, }\end{array}$ & Taiwan \\
\hline Corso, $\mathrm{M}$. & 2 & $\begin{array}{l}\text { Politecnico di Milano, Department of Management, Economics and Industrial Engineering, } \\
\text { Milan, }\end{array}$ & Italy \\
\hline Devinney, $\mathrm{T}$. & 2 & University of Leeds, Leeds & $\mathrm{UK}$ \\
\hline Greenfield, D. & 2 & $\begin{array}{l}\text { Macquarie University, Centre for Healthcare Resilience and Implementation Science, North } \\
\text { Ryde, }\end{array}$ & Australia \\
\hline Gressgård, L.J. & 2 & International Research Institute of Stavanger, Stavanger, & Norway \\
\hline Harvey, G. & 2 & University of Adelaide, Nursing school, Adelaide, & Australia \\
\hline Krive, J. & 2 & Nova Southeastern University, Biomedical Informatics Program, Fort Lauderdale, & USA \\
\hline Lindberg, A. & 2 & UC Berkeley, School of Social Welfare, Berkeley, & USA \\
\hline Nugus, P. & 2 & McGill University, Centre for Medical Education, Montreal, & Canada \\
\hline Runciman, W. & 2 & University of South Australia, Adelaide, & Australia \\
\hline Taifi, N. & 2 & Ecole Mohammadia d'Ingenieurs, Department of Industrial Engineering, Agdal Rabat, & Marocco \\
\hline Travaglia, J. & 2 & University of Technology Sydney, Faculty of Health Sydney, & Australia \\
\hline Tsai, C.W. & 2 & $\begin{array}{l}\text { National Taiwan Normal University, Department of Human Resource Development and } \\
\text { Applied Technology, Taipei, }\end{array}$ & Taiwan \\
\hline $\begin{array}{l}\text { Van Engelen, } \\
\text { J.M.L. }\end{array}$ & 2 & Delft University of Technology, Department of Industrial Design, Delft, & Netherlands \\
\hline Westbrook, J. & 2 & Macquarie University, Australian Institute of Health Innovation, North Ryde, & Australia \\
\hline
\end{tabular}

Another quantitative analysis performed from a bibliometric look is related to the number of authors that appear in the result of this search, which allows to affirm that there is no author that stands out in this line of research. The area is under construction and development and the researchers who work in it are still varied in numbers. In Table 1 we organized the main authors in this area, being mentioned for having at least 2 publications indexed in the Scopus database.

Based on Table 1, the number of publications, the university of origin and the respective country is also described, and it can be observed that of the 21 authors who stand out with debates and publications on this subject 8 are from Australia, followed by Taiwan with 3 publications. Even though the United States is the country that publishes the most, it is in third place of prominent authors with greater number of publications.

Based on the general survey, it was possible to analyze the areas of concentration of articles that are in the following fields of knowledge: Social Sciences, Business, Management and Accounting, Computer Science, 


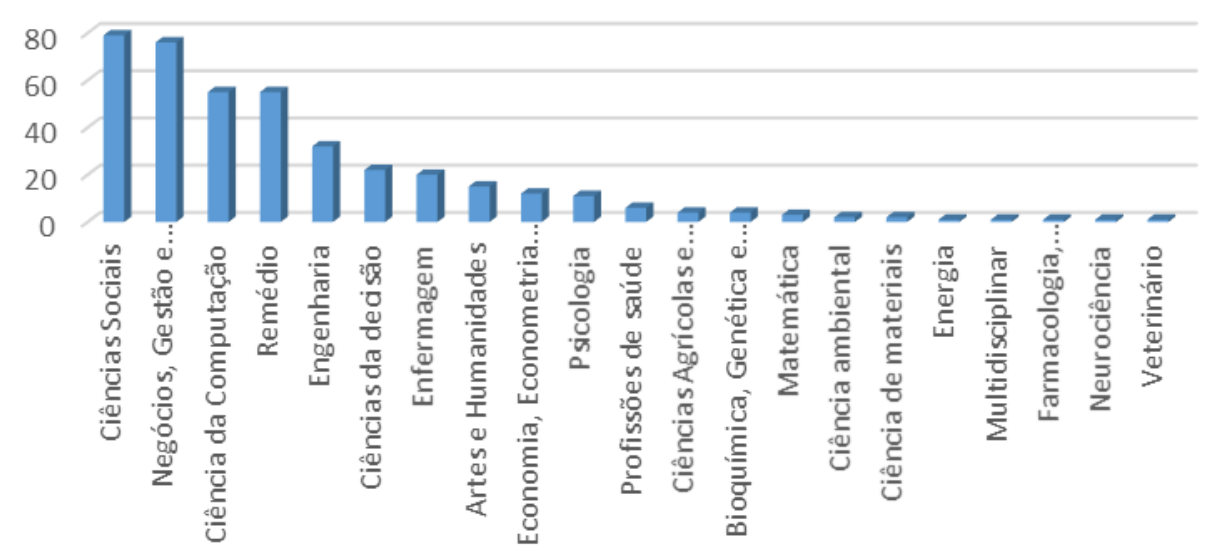

Figure 4. Areas of knowledge of the publication Source: Authors (2017)

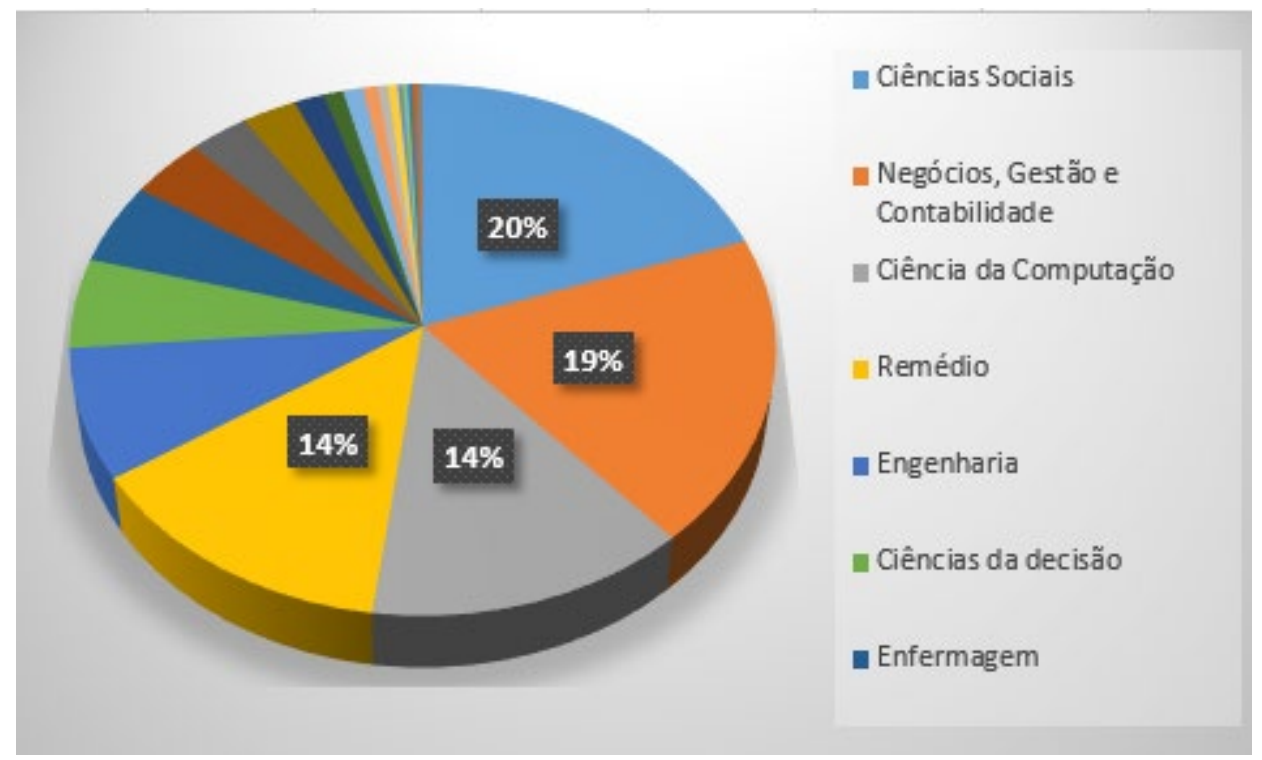

Figure 5. Analysis of the percentage of areas of knowledge of the publication

Source: Authors (2017)

Medicine, Engineering, Decision Sciences, Nursing, Arts and Humanities, Economics, Econometrics and Finance, Psychology, aligned Health Professions, Agricultural and Biological Sciences, Biochemistry, Genetics and Molecular Biology, Energy, Environmental Science, Mathematics, Materials Science, Multidisciplinary, Neuroscience, Pharmacology, Toxicology and Pharmaceutical and Veterinary, as Figure 4 illustrates.

The largest number of publications is in the area of Social Sciences with $20 \%$ of publications, followed by Business, Management and Accounting with 19\% and Computer Science and medicine with 14\%, according to Figure 5 .

Another analysis conducted, from the bibliometric analysis, based on the group of works retrieved from the Scopus database, were the keywords used that synthesized in 140 different words. The highlight was the keyword Human with 66 occurrences, followed by article with 64, Innovation with 55, Knowledge management with 54, knowledge sharing with 54. Followed by innovation diffusion with 40, mass communication with 37 , communication with 36, organization and management with 26, Organizational innovation with 26, organization with 23, Interpersonal communication with 21, Learning with 19, dissemination of information with 16 , methodology with 16, Information technology with 15, United States with 15, Education with 14, Female with 14 followed by Attitude of health personnel, Internet, Knowledge, Journal of Priority with 14 repetitions and with 13 repetitions appear the words: Health Quality, Information Management, Knowledge Transfer, Male and with 12 
words: Adult, Cooperative behavior and with 11 Health Services Research. The other occurrences were not considered in this article, because they appear with a frequency considered low being 10 times only.

In the analysis of the keywords, it is noticed that the discussion about innovation, knowledge sharing, innovation and communication in the teaching and learning process brings together the themes "Human", "Innovation", "Knowledge management" and "Knowledge sharing" with an emphasis on an active proposal to teach and learn in the educational setting and in the business world which characterizes the demand for new ways of sharing knowledge.

Finally, searching for a qualitative analysis, it was noticed that this debate also involves concern with public policies focused on innovation, sharing through communication and social networks in the globalized world where knowledge is the factor of production. However, it was not identified despite the relevance and emphasis of the topic in the practice of knowledge sharing in current society discussions permeating communication and innovation in the knowledge age.

\section{CONCLUSION}

Communication is an important tool in the transformation process that occurs between data, information and knowledge that generates innovation in society. The intersection between communication that turn on cities, states, and countries and that synchronously links people in the most diverse regions allows the sharing of information ideas and these provide the knowledge that when explicit, and the one that drives the innovative breakthroughs in an organization.

To deal with communication, innovation and knowledge sharing in a globalized world involves discussing aspects related to innovative technologies that disseminate knowledge through innovative tools that form a critical and autonomous subject in the different dimensions of society. The scientific mapping of production related to the theme "communication, innovation and knowledge", made in the Scopus database, allowed a bibliometric analysis of the theme describing the main discussions of contemporaneity and the intersection between the areas. As result, it was identified that the research emerges in the multidisciplinary field, intersecting the discussions Social Sciences, Business, Management and Accounting, Computer Science, Medicine, Engineering, Decision Sciences, Nursing, Arts and Humanities, Economics, Econometrics and Finance, Psychology, aligned Health Professions, Agricultural and Biological Sciences, Biochemistry, Genetics and Molecular Biology, Energy, Environmental Science, Mathematics, Materials Science, Multidisciplinary, Neuroscience, Pharmacology, Toxicology and Pharmaceutical and Veterinary.

With this research, it was found that knowledge networks connected to communication bridges that provide the exchange of messages, information, and data that make value assets that are intertwined and related to be the driving force for innovation in an organization. It is proposed that studies in different areas be analyzed by an integrated view of new ways of communicating and sharing knowledge both in the educational and in the business world, promoting networks of information that lead the human being to new scenarios.

The theme lacks research that integrates globalization with communication, innovation and knowledge. Therefore, studies are suggested that contemplate themes about different forms of knowledge sharing using different technologies in the educational scenario and in the business world.

\section{REFERENCES}

Banerjee, P. (2013). Ethical issues in our times of technology: Select exploration. AI and Society, 28(4), 383-388. https://doi.org/10.1007/s00146-013-0514-7

Bejinaru, R. and Băeșu, C. (2017). Connecting Approaches of Innovation and Organizational Change in Business Companies. Usv Annals of Economics \& Public Administration, Romania, 2(17), 87-94.

Boyce, R. A. (2015). Symbolic power and professional titles: The case of "podiatric surgeon". Health Sociology Review, 24(3), 310-322. https://doi.org/10.1080/14461242.2015.1051081

Braithwaite, J., Herkes, J., Ludlow, K., Testa, L. and Lamprell, G. (2017). Association between organisational and workplace cultures, and patient outcomes: Systematic review protocol. BMJ Open, 6(12), e 013758. https:// doi.org/10.1136/bmjopen-2017-017708

Chamon, E. O. (2007). Gestão e comportamento bumano nas organizações. Rio de Janeiro: Brasport.

Chang, C.-C., Liang, C., Shu, K.-M. and Chiu, Y.-C. (2015). Alteration of influencing factors of e-learning continued intention for different degrees of online participation. International Review of Research in Open and Distance Learning, 16(4), 33-61. https://doi.org/10.19173/irrodl.v16i4.2084

Delmas, M. A. and Pekovic, S. (2016). Corporate Sustainable Innovation and Employee Behavior. Journal of Business Ethics, 150(4), 1071-1088. Springer Nature. https:/ doi.org/10.1007/s10551-016-3163-1 
Devinney, T. M. (2015). PWC strategy \& eminent scholar in international management. Advances in International Management, 28, 3-4. https://doi.org/10.1108/S1571-502720150000028001

Dostie, B. (2017). The Impact of Training on Innovation. Ilr Review, 71(1), 64-87. SAGE Publications. https://doi.org/10.1177/0019793917701116

Feather, J. and Sturges, R. P. (2003). International encyclopaedia of information and library science.

Gastaldi, L. and Corso, M. (2013). Academics as effective orchestrators of interorganizational change and development: The experience of Italian Observatories. Research in Organizational Change and Development, 21, 59119. https://doi.org/10.1108/S0897-3016(2013)0000021006

Goergen, S., Schultz, T., Deakin, A. and Runciman, W. (2015). Investigating errors in medical imaging: Lessons for practice from medicolegal closed claims. Journal of the American College of Radiology, 12(9), 988-997. https://doi.org/10.1016/j.jacr.2015.03.025

Greenfield, D. (2016). The impact of national accreditation reform on survey reliability: a 2-year investigation of survey coordinators' perspectives. Journal of Evaluation in Clinical Practice, 22(5), 662-667. https://doi.org/10.1111/jep.12512

Gressgård, L. J. (2014). Knowledge exchange systems usage: The importance of content contribution and application in distributed environments. Journal of Knowledge Management, 18(2), 329-341. https://doi.org/10.1108/JKM-09-2013-0339

Harvey, G. and Kitson, A. (2016). PARIHS revisited: From heuristic to integrated framework for the successful implementation of knowledge into practice. Implementation cience, 11(1), 33. https://doi.org/10.1186/s13012016-0398-2

IPE, M. (2003) Knowledge Sharing in Organizations: A Conceptual Framework. Human Resource Development Review, 2(4), 337- 359. https://doi.org/10.1177/1534484303257985

Krive, J. (2015). Patient Outcomes as Transformative Mechanisms to Bring Health Information Technology Industry and Research Informatics Closer Together. Studies in Health Technology and Informatics, 216, 410-413.

Lakatos, E. M. and Marconi, M. de A. (2010). Fundamentos de metodologia científica. São Paulo: Atlas.

Lin, H. (2017). Antecedents and consequences of electronic supply chain management diffusion: The moderating effect of knowledge sharing. International Journal of Logistics Management, 28(2), 699-718. https://doi.org/10.1108/IJLM-01-2016-0023

Lindberg, A. (2012). A Senior Manager with a Knowledge Management Portfolio: The Santa Clara County Experience. Journal of Evidence-Based Social Work, 9(1-2), 110-120. https://doi.org/10.1080/15433714.2012.636316

Lutz, J., Smetschka, B. and Grima, N. (2017). Farmer Cooperation as a Means for Creating Local Food SystemsPotentials and Challenges. Sustainability, 9(6), 925-941. https://doi.org/10.3390/su9060925

Lyytinen, K., Ann, M. and Michael, S. (2017). Digital Innovation Management: Reinventing Innovation Management Research In A Digital World. Mis Quarterly, Usa, 41(1), 223-238. https://doi.org/10.25300/MISQ/2017/41:1.03

Moussa, M., Mcmurray, A. and Muenjohn, N. (2018). A Conceptual Framework of the Factors Influencing Innovation in Public Sector Organizations. The Journal Of Developing Areas, 52(3), 231-240. https://doi.org/10.1353/jda.2018.0048

Nugus, P. and Braithwaite, J. (2015). Harold Garfinkel: Lessons on emergent behaviours in complex organisations (Book Chapter). The Palgrave Handbook of Social Theory in Health, Illness and Medicine pp. 251-261

Olokundun, M., et al. (2018). Intrapreneurship and Innovation Performance: A Conceptual Model. Academy Of Strategic Management Journal, London, 2(17), 1-5.

Passiante, G. (2016). Knowledge-Intensive Entrepreneurship: Dynamics and Impact. International Journal of Innovation and Tecbnology Management, 13(5), 1602002. https:/ / doi.org/10.1142/S0219877016020028

Pavlov, P. (2017). Innovation Strategies in the Industrial Enterprises of the Varna Region. Economic Archive, Fakultetsgatan, 1(1), 42-55.

Santos, R. N. M. and Kobashi, N. Y. (2009). Bibliometria, cientometria, infometria: conceitos e aplicações. Tendências da Pesquisa Brasileira em Ciência da Informação, 2(1), 155-172.

Taifi, N. (2014) . Non-typical race cat shows: The domino effect. International Journal of Sustainability Policy and Practice, 9(2), 29-35. https:// doi.org/10.18848/2325-1166/CGP/v09i02/55420

Travaglia, J. F., Dawson, G., Gilmour, R. and Tobin, S. (2016). Strengthening public health systems: Assessing the attributes of the NSW influenza surveillance system. Public Health Research and Practice, 26(2), e2621621.

Tsai, C. and Chang, C.-C. (2012). Developing a knowledge management behavior scale of e-portfolio based on approaches of web fuzzy Delphi and fuzzy AHP. Journal of Educational Media and Library Science, 50(1), 103-134.

Van Engelen, Jo M. L. J., Wever, R., Brezet, J., De Koning, J. and Crul, M. (2016). Mental innovation space of Vietnamese agro-food firms. British Food Journal, 118(6), 1516-1532. https://doi.org/10.1108/BFJ-10-20150400 
Westbrook, J. I., Page, N. and Baysari, M. T. (2017). A systematic review of the effectiveness of interruptive medication prescribing alerts in hospital CPOE systems to change prescriber behavior and improve patient safety. International Journal of Medical Informatics, 105, 22-30. https:// doi.org/10.1016/j.ijmedinf.2017.05.011

Yuan, Y-H., et al. (2017). An empirical research on relationships between subjective judgement, technology acceptance tendency and knowledge transfer. Plos One, 12(9), 375-404. https://doi.org/10.1371/journal.pone.0183994

Zonta, T. C. and Amal, M. (2018) Internationalization and innovation: The case of a born global from Brazil. Internext, 13(1), 63-74. https://doi.org/10.18568/1980-4865.13163-76 